\title{
DES + EQUILIBR + ISTA(S): A POÉTICA E O SIGNO LINGUÍSTICO
}

\author{
DES + EQUILIBR + ISTA(S): LA POÉTICA Y EL SIGNO LINGÜÍSTICO
}

\author{
Adriane Ester Hoffmann ${ }^{1}$ \\ Rita de Cássia Dias Verdi Fumagalli
}

\begin{abstract}
RESUMO: O presente trabalho discorre sobre a obra Desequilibristas, de Manu Maltez. Objetiva-se analisar a poética contemporânea do artista e escritor, desvelando o universo do skate. A pesquisa tem como referencial teórico Saussure (1969), Benveniste (2005) e Jakobson (1975) com as noções de valor do signo, do signo enquanto sistema, das unidades da língua nos planos sintagmático e paradigmático e da função poética. Ainda, o aparato teórico está fundamentado em Merquior (1997), que discorre sobre o âmbito da literatura contemporânea e se dedica ao assunto, enfocando o viés mimético e a tessitura verbal que constituem o fundamento da lírica. Afirma que a poesia lírica tem sido abordada teoricamente sobretudo a partir de sua relação com a representação e do seu modo de ser como linguagem. A metodologia utilizada é a de análise dos poemas que constituem a obra Desequilibristas, de Manu Maltez. Percebeu-se, no decorrer da análise, que a obra corrobora a noção de que o signo, em um sistema linguístico, pode assumir significações diversas e de que sintagmas e paradigmas auxiliam na compreensão da obra poética.
\end{abstract}

Palavras-chave: Poética; signo linguístico; skate.

RESUMEN: El presente trabajo discurre sobre la obra Desequilibristas, de Manu Maltez. El objetivo es analizar la poética contemporánea del artista y escritor, desvelando el universo del skate. La investigación tiene como referencia teórico Saussure (1969), Benveniste (2005) y Jakobson (1975) con las nociones de valor del signo, del signo como sistema, de las unidades de la lengua en los planos sintagmático y paradigmático y de la función poética. Además, el aparato teórico está fundamentado en Merquior (1997), que discurre sobre el ámbito de la literatura contemporánea y se dedica al tema, enfocando el sesgo mimético y la tesitura verbal que constituyen el fundamento de la lírica. Afirma que la poesía lírica ha sido abordada teóricamente sobre todo a partir de su relación con la representación y de su modo de ser como lenguaje. La metodología utilizada es la de análisis de los poemas que constituyen la obra Desequilibristas, de Manu Maltez. Se percibió, en el transcurso del análisis, que la obra corrobora la noción de que el signo, en un sistema lingüístico, puede asumir significados diversos y de que sintagmas y paradigmas auxilian en la comprensión de la obra poética.

Palabras-clave: Poética; signo lingüístico; skate.

\section{Palavras iniciais}

O presente trabalho discorre sobre a obra Desequilibristas, de Manu Maltez. Objetiva-se analisar a poética contemporânea do artista e escritor, desvelando o universo do skate. $\mathrm{O}$

\footnotetext{
${ }^{1}$ Doutoranda em Letras pela Universidade de Passo Fundo-UPF. Professora na Universidade Regional Integrada do Alto Uruguai e das Missões-URI/FW.

${ }^{2}$ Doutora em Letras pela Universidade de Passo Fundo-UPF.
} 
paulista Manu Maltez é escritor, desenhista e músico. Graduado em música, contrabaixista, compositor e intérprete, além de artista plástico, escritor e cineasta.

Em seu site, Manu Maltez disponibiliza informações referentes à sua carreira artística. Assim, como artista plástico, realizou diversas exposições de suas gravuras e desenhos. É conhecido também por intervenções plásticas em locais públicos e instalações sonoras. Seu universo literário/gráfico também é rico. É autor de cinco livros lançados no Brasil: O Corvo, pela Editora Scipione, em 2010. Recebeu os Prêmios FNLIJ e Jabuti por essa obra; Meu Tio Lobisomem - Uma história verídica, lançado pela Editora Peirópolis, em 2011. Por esse trabalho, recebeu os Prêmios: Biblioteca Nacional, Selo Altamente Recomendável FNLIJ e White Ravens; O Diabo Era Mais Embaixo, pela Editora Scipione, em 2012. Recebeu o Selo FNLIJ Altamente Recomendável e Catálogo Feira de Bolonha, em 2013; O Último Livro do Mundo, Edições SESC, em 2013; e Desequilibristas, pela Editora Peirópolis, em 2014. Essa obra rendeu ao artista: catálogo Feira de Bolonha, em 2015; catálogo White Ravens - Biblioteca de Munique; e recebeu o Prêmio FNLIJ, de melhor livro para jovens, produção 2014.

A pesquisa tem como referencial teórico Saussure (1969), Benveniste (2005) e Jakobson (1975) com as noções de valor do signo, do signo enquanto sistema, das unidades da língua nos planos sintagmático (relações de combinação) e paradigmático (relações de substituição) e da função poética.

Ainda, o aparato teórico está fundamentado em Merquior (1997), pois esse autor discorre sobre o âmbito da literatura contemporânea e se dedica ao assunto, enfocando o viés mimético e a tessitura verbal que constituem o fundamento da lírica. Afirma que a poesia lírica tem sido abordada teoricamente sobretudo a partir de sua relação com a representação e do seu modo de ser como linguagem.

\section{Pontos e contrapontos linguísticos e estéticos}

De acordo com Saussure (1969), a língua não é um sistema de valores puro, porque inclui em seu sistema ideias e sons. Se não existissem os signos, não teríamos capacidade para distinguir as ideias. A substância fônica é uma matéria plástica que se divide em partes distintas para fornecer significantes aos pensamentos. Assim,

O papel característico da língua frente ao pensamento não é criar um meio fônico material para a expressão das ideias, mas servir de intermediário entre o pensamento e o som, em condições tais que uma união conduza necessariamente a delimitações recíprocas de unidades. (SAUSSURE, 1969. p. 131).

Nesse sentido, não há materialização de pensamento e nem espiritualização de sons. $\mathrm{Na}$ língua, há articulações, em que cada termo linguístico é um membro em que se fixam uma ideia e um som. Com isso, um som se torna o signo de uma ideia. A língua, nesse processo, não pode isolar o som do pensamento ou o pensamento do som. A Linguística trabalha no limite entre esses dois elementos, combinando-os para produzir uma forma. Saussure (1969, p. 81) afirma que: 
O laço que une o significante ao significado é arbitrário ou então, vista que entendemos por signo o total resultante da associação de um significante com um significado, podemos dizer mais simplesmente: o signo linguístico é arbitrário.

A arbitrariedade do signo auxilia para que se compreenda por que o fato social pode, por si só, criar um sistema linguístico. Assim, a coletividade é importante para estabelecer valores que se justificam pelo uso e pelo consenso. Ainda, a ideia de valor não é uma soma de sons e de conceitos, mas parte da totalidade solidária para obter significante e significado.

O valor, então, para Saussure (1969, p. 133) "constitui um elemento da significação, e é difićlimo saber como esta se distingue dele, apesar de estar sob sua dependência”. A partir dessa assertiva, percebe-se uma correlação entre imagem auditiva e conceito. No entanto, há um aspecto paradoxal: o conceito é a contraparte da imagem auditiva no interior do signo; e, a relação que une seus dois elementos é a contrapartida dos outros signos da língua. Para o linguista, mesmo o valor estando fora da língua, ele continua regido pelo paradoxo. Isso significa afirmar que:

$1^{\circ}$ por uma coisa dessemelhante, suscetível de ser trocada por outra cujo valor resta determinar; $2^{\circ}$ por coisas semelhantes que se podem comparar com aquela cujo valor está em causa. (SAUSSURE, 1969. p. 134).

Esses fatores são necessários para a existência de um valor, porque uma palavra pode ser trocada por outra dessemelhante, que pode ser uma ideia. Também, pode ser comparada com algo da mesma natureza, uma palavra. Ressalta que, se os valores correspondem a conceitos, subentende-se que são puramente diferenciais, não por seu conteúdo, mas por suas relações com os outros termos do sistema.

Com isso,

Se a parte conceitual do valor é constituída unicamente por relações e diferenças com os outros termos da língua, pode-se dizer o mesmo de sua parte material. O que importa na palavra não é o som em si, mas as diferenças fônicas que permitem distinguir essas palavras de todas as outras, pois são elas que levam a significação. (SAUSSURE, 1969. p. 136-137).

A partir do exposto, constata-se que Saussure conceitua arbitrário e diferencial como sendo duas qualidades correlativas. Corrobora essa definição, explicando que um fragmento de língua não pode se basear em outra coisa que não seja sua não-coincidência com o resto. Dessa forma, para considerar o signo em sua totalidade, evidencia que na língua só existem diferenças. A prova disso é que o "valor de um termo pode modificar-se sem que lhe toque quer no sentido quer nos sons, unicamente pelo fato de um termo vizinho ter sofrido uma modificação". (SAUSSURE, 1969. p. 139).

Um sistema linguístico, nessa perspectiva, é uma série de diferenças de sons combinadas com uma série de diferenças de ideias; no entanto, essa confrontação de signos acústicos com o pensamento produz um sistema de valores, que constitui o vínculo efetivo entre os elementos fônicos e psíquicos no interior de cada signo. 
Assim,

conquanto o significado e o significante sejam considerados, cada qual à parte, puramente diferenciais e negativos, sua combinação é um fato positivo; é mesmo a única espécie de fatos que a língua comporta, pois o próprio da instituição linguística é justamente manter o paralelismo entre essas duas ordens de diferenças. (SAUSSURE, 1969. p. 140).

Para complementar essa noção de valor, Saussure afirma que o princípio da diferenciação pode ser aplicado também à unidade. Isso, porque "os caracteres da unidade se confundem com a própria unidade”. (SAUSSURE, 1969. p. 140). Complementa, afirmando que na língua, e em todo sistema semiológico, o que distingue um signo é tudo o que o constitui, pois a diferença é o que faz a característica, como faz o valor e a unidade.

As relações a as diferenças entre termos linguísticos se desenvolvem em duas esferas distintas, em que cada uma é geradora de valores. A oposição entre elas faz compreender melhor a sua natureza. O linguista destaca que no discurso, os termos estabelecem entre si, em um encadeamento, "relações baseadas no caráter linear da língua, que exclui a possibilidade de pronunciar dois elementos ao mesmo tempo. Estes se alinham um após outro na cadeia da fala”. (SAUSSURE, 1969. p. 142).

Tais combinações podem ser chamadas de sintagmas, que se constituem de duas ou mais unidades consecutivas. Por outro lado, fora do discurso, as palavras podem oferecer algo em comum que se associa à memória e, com isso, formam grupos com relações diversas. Então,

a relação sintagmática existe in praesentia; repousa em dois ou mais termos igualmente presentes numa série efetiva. Ao contrário, a relação associativa une termos in absentia numa série mnemônica virtual. (SAUSSURE, 1969. p. 143).

Esses conceitos são detalhados pelo linguista, ao afirmar que a noção de sintagma se aplica não só às palavras, mas aos grupos de palavras, às unidades complexas de toda dimensão e de toda espécie. Isso equivale a dizer que não basta considerar a relação que une entre si as diversas partes de um sintagma, mas também levar em conta a que liga o todo com as diversas partes. A partir disso, Saussure reconhece que "no domínio do sintagma não há limite categórico entre o fato de língua, testemunho de uso coletivo, e o fato de fala, que depende da liberdade individual". (SAUSSURE, 1969. p. 145).

Em referência às relações associativas, os grupos formam-se ao aproximar termos que apresentam algo em comum, por analogia de significados e/ou pela comunidade de imagens acústicas. Assim,

enquanto um sintagma suscita em seguida a ideia de uma ordem de sucessão e de um número determinado de elementos, os termos de uma família associativa não se apresentam nem em número definido nem numa ordem determinada. (SAUSSURE, 1969. p. 146).

Portanto, uma palavra pode evocar tudo quanto seja suscetível de ser-lhe associado de uma maneira ou de outra, pois os termos de uma família associativa não se apresentam nem em 
número definido nem em uma determinada ordem.

Benveniste (2005) retoma os conceitos saussurianos de signo e corrobora que expressão e conteúdo, equivalem, respectivamente, a significante e a significado, e "são estabelecidos como dois planos correlativos, cada um dos quais comporta uma "forma" e uma "substância"”. (BENVENISTE, 2005.p. 14). Afirma que a teoria da linguagem, teorizada por Saussure, propôs um horizonte para a ciência e para a filosofia, pois a noção de signo como unidade bilateral, "contribuiu para o advento do pensamento formal nas ciências da sociedade e da cultura, e para a constituição de uma semiologia geral”. (BENVENISTE, 2005. p. 49).

Outro conceito discutido por Benveniste é a arbitrariedade do signo linguístico. Para ele, discutir o arbitrário é importante quando se analisa essa arbitrariedade em relação ao fenômeno ou ao objeto material, o que não interfere na constituição do signo. Retoma a percepção saussuriana de que é possível entender o signo pela sua imutabilidade e sua mutabilidade:

imutabilidade porque, sendo arbitrário, não pode ser discutido em nome de uma norma razoável; mutabilidade, porque, sendo arbitrário, é sempre suscetível de alterar-se. (BENVENISTE, 2005. p. 57-58).

Afirma que o mérito dessa concepção está na relação entre signo e objeto, que se modifica e permanece imutável. O que acrescenta é que há uma motivação objetiva à luz de fatores históricos e, com isso, a noção de significação permanece, mas a noção de signo é modificada. Para complementar sua teoria, Benveniste discute o conceito de valor, expondo que quando se considera o signo em si mesmo e enquanto portador de um valor, o arbitrário se encontra eliminado. Defende, então, que "o valor é um elemento do signo; se o signo tomado em si mesmo não é arbitrário, segue-se que o caráter "relativo" do valor não pode depender da natureza "arbitrária" do signo". (BENVENISTE, 2005. p. 59).

Complementa seu raciocínio, afirmando que deve-se considerar o valor apenas como um atributo da forma, não da substância. Por isso, acredita que os valores são relativos uns aos outros e defende que é importante considerar o signo não de forma isolada, mas como sistema. Destaca que "a relatividade dos valores é a melhor prova de que dependem estreitamente uns dos outros na sincronia de um sistema sempre ameaçado, sempre restaurado”. (BENVENISTE, 2005.p. 59).

Tal concepção está alicerçada na ideia de que todos os valores são de oposição e não se definem a não ser pela sua diferença. Assim, uma vez opostos, conservam-se em uma relação mútua de necessidade. Pensar a língua, nessa perspectiva, é aceitar o princípio fundamental da linguística moderna, segundo Benveniste, que é o de que a língua forma um sistema. E, para o linguista, cada uma das unidades de um sistema define-se pelo conjunto das relações que mantém com outras unidades e pelas oposições entre elas.

O fato linguístico é constituído por relações, em que cada elemento é uma parte de um conjunto sincrônico. Dessa forma,

as unidades da língua dependem, realmente, de dois planos: sintagmático, quando se encaram nas suas relações de sucessão material no seio da cadeia falada, paradigmático quando se propõem em razão de possível substituição, cada uma no seu nível e dentro da sua classe formal. (BENVENISTE, 2005.p. 
23).

Portanto, descrever essas relações é referir-se à estrutura formal da língua. Formalizar essa descrição é torná-la cada vez mais concreta, reduzindo a língua aos elementos significantes de que ela se compõe e definindo esses elementos pela sua dependência mútua. Assim, pode-se caracterizar uma estrutura linguística pela sua distribuição e pelas suas combinações possíveis.

Jakobson (1975) afirma que há relação entre linguística e poética na medida em que a poética trata de problemas referentes à estrutura verbal e a linguística é a ciência global da estrutura verbal. Com isso, os traços poéticos pertencem à ciência da linguagem, no que tange à teoria dos signos, uma vez que o comportamento verbal pode ser realizado de dois modos, pela seleção e pela combinação.

Jakobson apresenta uma definição para a metalinguagem, que fala da linguagem. Sempre que o remetente e/ou destinatário têm necessidade de verificar se estão usando o mesmo código, o discurso focaliza o código, assim, desempenha uma função metalinguística.

Ao se referir à função poética, o autor afirma que o estudo linguístico da função poética deve ultrapassar os limites da poesia. Também, que existem dois modos básicos de arranjos utilizados no comportamento verbal: seleção e combinação. A seleção é feita em base de equivalência, semelhança e dessemelhança, sinonímia e antonímia. A combinação, a construção da sequência, se baseia na contiguidade.

Com isso, conceitua que a função poética projeta o princípio de equivalência do eixo de seleção sobre o eixo de combinação. E afirma que a metalinguagem também faz uso sequencial de unidades equivalentes quando combina expressões sinônimas em uma sequência equacional. Dessa forma, acredita que poesia e metalinguagem estão em oposição; em metalinguagem a sequência é usada para construir uma equação, ao passo que em poesia é usada para construir uma sequência.

Para Jakobson (1975), falar implica a seleção de certas entidades linguísticas e usa combinação em unidades linguísticas de mais alto grau de complexidade. O destinatário percebe que o enunciado dado (mensagem) é uma combinação de partes constituintes (frases, palavras, fonemas, etc.) selecionadas do repertório de todas as partes constituintes possíveis (código). Os constituintes de um contexto têm um estatuto de contiguidade, enquanto em um grupo de substituição os signos estão ligados entre si por diferentes graus de similaridade, que oscilam entre a equivalência dos sinônimos e o fundo comum dos antônimos.

A poesia visa ao signo. O princípio de similaridade domina a poesia; o paralelismo métrico dos versos ou a equivalência fônica das rimas impõem o problema da similitude e do contraste semântico.

Após discorrer sobre aspectos linguísticos, é importante demonstrar em que medida essa ciência dialoga com a literatura. Assim, escolheu-se a literatura contemporânea, mais precisamente a poesia lírica para realizar uma análise. Isso, porque o gênero poético tem sido abordado, teoricamente, sobretudo a partir de sua relação com a representação e do seu modo de ser como linguagem.

Examinando a posição de Merquior (1997), verifica-se que a base do seu pensamento teórico concilia poesia com representação, no sentido aristotélico, e reforça a existência de uma 
função linguística específica para a lírica. Para o autor, "poesia é o tipo de mensagem linguística em que o significante é tão visível quanto o significado”. (MERQUIOR, 1997. p. 17). Por isso, a escolha da palavra é tão importante quanto o significado do vocábulo no contexto em que está inserido.

Valendo-se dos estudos linguísticos de Roman Jakobson e da teoria da mímese de Aristóteles, na Poética, Merquior (1997) propõe a seguinte conceituação para o texto lírico:

Poema é uma espécie de mensagem verbal fortemente regida, quanto ao funcionamento da linguagem, pela projeção do princípio de equivalência do plano da seleção das palavras para o plano de sua sequência na frase. Esta mensagem consiste na imitação de estados de ânimo (stasis), e tem por finalidade a transmissão indireta, por meio de estímulos não puramente intelectuais, de um conhecimento especial acerca da existência considerado de interesse permanente para a humanidade. (MERQUIOR, 1997. p. 27).

A linguagem poética expressa por um uso sequencial de unidades submetidas a poucos paradigmas, insiste na representação de mesmos elementos emotivos, os quais se intensificam pelo espelhamento interno também do significante. A mímese interna e o aprofundamento da interiorização são especificações linguísticas e psicológicas peculiares ao gênero lírico. A função poética da linguagem, que projeta o princípio de equivalência do eixo de seleção sobre o eixo da contiguidade, mostra que a estrutura do poema é uma das formas de representação da existência.

A presença de imagens poéticas, representativas da pluralidade do real, a existência do ritmo, direcionador da significação do poema, são também demonstrações de que a poesia vive nas camadas mais profundas do ser e de que ela imortaliza a existência humana.

\section{Princípios linguísticos e poéticos em Desequilibristas:}

A obra Desequilibristas, de Manu Maltez, é composta por poemas para serem declamados, conforme está exposto entre parênteses: "texto para declame em vias públicas, sobre um skate, pela cidade em chamas". (MALTEZ, 2014). Tal aspecto instiga o leitor a realizar sua leitura e participar da aventura que o contato com o skate proporciona, pois é convidado a vivenciar o que esse esporte propicia e tornar-se um desequilibrista.

Esse aspecto declamatório é percebido, na obra, em diferentes situações. Uma é a marcação linguística da conversação, como em "Olhaí passando mais um desequilibrista!". (MALTEZ, 2014). Outra, como se fosse uma apresentação circense: "Senhoras e senhores!”. (MALTEZ, 2014). Ainda, a presença de interrogações, como que dialogando com o público: "Mas também queria o quê?" (MALTEZ, 2014). Também, a representação gráfica dos poemas em tamanhos diferentes sugere a oralidade, que em determinadas situações, modifica-se o tom de voz a partir da intencionalidade do falante. O exemplo, retirado do livro, demonstra isso: 


\section{REDIME ESSE BUZINACO NOSSO MOTORIZADO GANSACOO \\ ESSA MANIA DE \\ AR CONDICIONADO \\ E OFERECE À FAUNA DOS BUEIROS \\ O SANGUE \\ QUE TE PINGA \\ DOS JOELHOS}

Fonte: MALTEZ (2014)

O poeta e artista, em sete momentos distintos, reforça o universo dos skatistas, chamando-os de desequilibristas. Ao fazer uma análise do signo linguístico, percebe-se que essa palavra é composta pelo radical /equilibr/, que tem origem latina "aequilibratus" (CUNHA, $\mathrm{s} / \mathrm{d}$, 309). Possui o sufixo nominal -ista, que também tem origem latina e pode designar: "partidários ou sectários de doutrinas ou sistemas artísticos, filosóficos, políticos ou religiosos; adeptos de divertimentos, de esportes”. (CUNHA, s/d, 448-449).

A origem da palavra equilibrista, então, sugere que os skatistas praticam um esporte. $\mathrm{O}$ prefixo - des, segundo o dicionário etimológico, possui noções básicas de:

coisa (ou ação) contrária àquela que é expressa pelo termo primitivo; cessação de algum estado primitivo ou de uma situação anterior; coisa ou ação mal feita; negação de qualidade expressa pelo termo primitivo; separação de alguma coisa de outra; mudança de aspecto. (CUNHA, s/d, 249).

Assim, a palavra desequilibrista possui uma significação negativa, observando-a descontextualizadamente, como Saussure defendia. Porém, durante toda a obra, em análise, um desequilibrista é um ser com o dom de fazer manobras radicais, de sobreviver nas ruas dos centros urbanos, dividindo o espaço com carros e pessoas, que acredita que sua arte embeleza a cidade e a vida dos transeuntes.

Assim, na obra há referência ao desequilibrista como: "ressuscitado do asfalto", "flanador calejado", "sonhador esfolado”, "palhaço cinzento”, "punk-passista”, "percussionista ambulante" e "ritmista ambulante" (MALTEZ, 2014). O que evidencia que a palavra dentro de um sistema, como afirma Benveniste, assume uma significação diferente da habitual. Deixa de ter uma carga negativa e passa a ter um aspecto positivo, porque um desequilibrista, na obra, é um ser dotado de coragem e persistência para aprender a fazer manobras, cair, levantar e continuar realizando a sua arte. O eixo paradigmático, a partir dos exemplos de sinonímia e/ou de adjetivação, confirma o caráter positivo do desequilibrista.

A sonoridade também é uma característica do livro de poemas analisado. A semelhança fônica sugere o som do skate raspando o concreto da cidade e o barulho das manobras. Assim, em "passando", "esqueça”, "esmigalhar", "raspa”, "tensão”, "desgasta” (MALTEZ, 2014) a 
repetição do som de /s/ sugere o barulho produzido pelos skatistas. A presença de onomatopeias também complementam a sonoridade característica desse esporte. É possível perceber isso, no seguinte trecho, há a presença de gírias, o que reforça a popularidade desse esporte.

\section{E VOCÊ, PRA ONDE VAI, MEU COMPANHEIRO? \\ COM ESSE SOLO IMPROVISADO DE BARULHINHOS RASCANTES \\ ESTALOS DE TAELÁAK \\ TRISCADOS DE BRISHHEH ViRLiLitiL \\ FRUINSIISHSHSHSHSHSHSHSHSHSP}

Fonte: MALTEZ, (2014).

Um exemplo desse populismo está em: "Parece beijar o chão./Só que não" (MALTEZ, 2014). A criação de neologismos corrobora que o skate está em toda a parte. O exemplo disso é: "Rema! Cidadanado". (MALTEZ, 2014).

Percebeu-se, no decorrer da análise, que a obra corrobora a noção de que o signo, em um sistema linguístico, pode assumir significações diversas e de que sintagmas e paradigmas auxiliam na compreensão da obra poética.

\section{Palavras finais}

A obra "Desequilibristas", de Manu Maltez, apresenta uma poética repleta de signos linguísticos que compõem o universo de skatistas, como, por exemplo: "pista", "cidade", “corrimão", "aerodinâmica”, "calçada”, "movimento", "parafuso", "ladeira”. Cada um desses sintagmas, para Saussure (1975), é um ato único cada vez que é pronunciado, mas pela sua noção de valor esse ato se concretiza e pode-se afirmar que cada um dos substantivos citados é do universo semântico do esporte em questão.

Para Saussure (1975), também, o valor é a contraparte dos termos coexistentes, ou seja, o valor de um termo está determinado por aquilo que o rodeia, por isso pode se modificar sem que se altere a sua significação. Isso implica afirmar que o signo "rema" é considerado um verbo, classificado sintaticamente como intransitivo, que pode significar, segundo o Dicionário Houaiss (2001, p. 242), "impulsionar embarcação por meio de remos; permanecer à superfície da água, sem afundar, nadar, boiar; avançar pelos ares; voar; voejar; enfrentar obstáculo ou realizar tarefa com ardor; trabalhar, lidar, lutar".

Tal designação para o verbo "remar" continua fazendo parte da constituição do signo linguístico. Porém, ele se modifica pelo conjunto de outros signos e passa a representar o movimento típico dos skatistas quando colocam um pé em cima do skate e com o outro fazem o movimento de impulso para conseguirem velocidade e agilidade.

Destaca-se, ainda a concepção de eixo sintagmático, entendendo o sintagma como tudo aquilo que é da competência do caráter linear da língua, espacial e temporal. As palavras se 
alinham uma após outra, em uma única extensão, em uma única dimensão tempo espacial, mantendo entre si uma relação de oposição.

Um exemplo desse eixo são as construções sintagmáticas da obra em análise: "pressente a aerodinâmica do acidente", "ajeita um pouco o gorro", "oferece à fauna dos bueiros o sangue que te pinga”, "empina o seu brinquedo revoltoso" (MALTEZ, 2014). Pelo citado, pode-se perceber que há sempre um sujeito elíptico, mais verbo de ação e complemento verbal ou adjunto adverbial. Entende-se, como leitor, que as ações, os movimentos, as manobras são repetidas, corriqueiras, em que o skatista é o sujeito da ação e dono de seu destino, de seu sucesso (ou não) nesse esporte.

Em relação ao eixo paradigmático, ele inclui a relação sintagmática, acrescenta informações do universo do skate com termos, referências e sonoridades para valorar a obra enquanto conjunto de elementos poéticos e linguísticos.

A partir dessa análise corrobora-se a importância de Saussure e Benveniste e de todos os estudiosos que se valem de seus ensinamentos para que se possa entender o sistema linguístico e entender o universos das obras existentes. Para, com isso, constituir-se um leitor mais consistente, exigente e com condições de discernir entre textos com qualidades sintagmática e paradigmática com aqueles que não possuem a riqueza do valor do signo e nem da cultura a que representam.

\section{Referências}

BENVENISTE, É. Problemas de Linguística Geral I. 5 ed. Campinas: Pontes Editores, 2005.

CUNHA, A. G. Dicionário etimológico da Lingua Portuguesa. São Paulo: Nova Fronteira, s/d.

FRIEDRICH, H. Estrutura da lírica moderna: da metade do século XIX a meados do século XX. São Paulo: Duas Cidades, 1991.

HOUAISS, A.; VILLAR, M. S. Dicionário Houaiss de Lingua Portuguesa. Rio de Janeiro: Objetiva, 2001.

JAKOBSON, R. Linguistica e comunicação. São Paulo: Cultrix, 1975.

MALTEZ, M. Desequilibristas. São Paulo: Peirópolis, 2014.

MALTEZ, M. Biografia. Disponível em: <http://www.manumaltez.com/\#!biografia/cjg9>. Acesso em: 06 jul. 2018.

MERQUIOR, J. G. A astúcia da mimese: ensaios sobre a lírica. Rio de Janeiro: Topbooks, 1997.

SAUSSURE, F. Curso de Linguística Geral. São Paulo: Cultrix, 1969.

Recebido em: 22/07/2019

Aceito em: 01/10/2019 